\title{
ISO 14062 in theory and practice-ecodesign procedure. Part 2: practical application
}

\author{
Przemyslaw Kurczewski • Anna Lewandowska
}

Received: 14 October 2009 /Accepted: 13 July 2010 / Published online: 7 August 2010

(C) The Author(s) 2010. This article is published with open access at Springerlink.com

\begin{abstract}
Purpose The goal of the paper is to present the ecodesign procedure developed based on the guidelines of ISO 14062 standard. The article has been divided into two parts. Part 1 (Lewandowska and Kurczewski 2010) presents the description of the procedure's structure and its most important elements. Part 2 focuses on the practical aspects and presents an example of the suggested methodology application in relation to a fridge freezer.

Methods The example presented uses the environmental life cycle assessment, life cycle costing, and environmental benchmarking, however, the use of other techniques, e.g. matrix methods, Social Life Cycle Assessment, checklists, is also possible. An innovation is the development of assessment criteria concerning the interested parties and their requirements and the use of multidimensional comparative analysis (MCA) in the assessment of the design variants.

Results and discussion The result of ecodesign application is the selection of the design that meets the assumed requirements to the highest extent. They are formulated not only on the basis of environmental or economic aspects, but also in virtue of the interested parties' requirements,
\end{abstract}

Responsible editor: Wulf-Peter Schmidt

P. Kurczewski

Institute of Combustion Engines and Transport, Faculty of Machines and Transport, Poznan University of Technology, ul. Piotrowo 3,

60-965 Poznan, Poland

A. Lewandowska $(\square)$

Product Ecology Department, Faculty of Commodity Science,

Poznan University of Economics,

Al. Niepodleglosci 10,

61-875 Poznan, Poland

e-mail: anna.lewandowska@ue.poznan.pl including: functionality, ergonomics, safety, etc. Ecodesign requires relatively quick and clear responses.

Conclusions The suggested procedure comprises all the key elements of ecodesign and the result represents a compromise solution between various, often contradictory, requirements identified at different life cycle stages. The suggested procedure has been checked on a few practical examples, although it still requires verification in relation to products/services of various groups and representing various specific features (electrical and electronic equipment, packages, clothes, furniture, services, etc.).

Keywords Ecodesign · Interested parties · ISO 14062 - Life cycle assessment (LCA) - Life cycle costing (LCC) . Multidimensional comparative analysis (MCA) . Requirements

\section{Planning}

The presentation of the practical application of the ecodesign procedure discussed in part 1 of this paper has been based on the example of a new refrigerator model development. At the start of the performance of the first stage - planning - the work was done in order to determine the following items:

- The fridge freezer to be recognized as the input in the design work,

- vision of a fridge freezer to meet the requirements of the parties interested and recommendations formulated after key analyses, e.g., life cycle assessment (LCA), life cycle costing (LCC), and social life cycle assessment (SLCA),

- technological advance difference as the future ecodesign effect. 
Below the particular steps included in the planning scope will be analyzed: appointing an ecodesign team (Section 1.1), definition of the target (Section 1.2), definition of the input condition (Section 1.3), definition of the target condition (Section 1.4), and formulation of conclusions from (Section 1.5) planning stage.

\subsection{Appointing the ecodesign team}

The appointed ecodesign team included the refrigerator manufacturer's representatives (employees of design, structural, technological and production, environmental, occupational health and safety, quality management, marketing and purchasing departments) and people from scientific institutions involved in ecodesign and product life cycle management. Service repair units, users, and recyclers of used electrical and electronic equipment have their contribution as well.

\subsection{Definition of the target}

Within the actions taken up, the target of the ecodesign process was assumed as the definition of selected refrigerator improvement directions towards environment friendliness, economic justifiability to meet the requirements of interested parties, including the EU ecolabel.

With the target so widely defined, the ecodesign scope included the following tasks:

- Identification of the main sources of environmental effect in the life cycle of the refrigerator being the reference object,

- identification of the main cost sources in the refrigerator's life cycle,

- identification of the most important interested parties appearing throughout the reference refrigerator's life cycle and the requirements set towards the refrigerator,

- definition of the designed refrigerator's development directions that would enable its reduced environmental effect and at the same time meet the requirements of the parties interested and definition of the economic consequences of some specific solutions,

- selection of the optimum solution.

\subsection{Definition of the input condition}

The key issue of ecodesign is to define the reference object (step 1.3.1 of ecodesign procedure presented in Part 1) (Lewandowska and Kurczewski 2010) that will constitute the starting point in the whole procedure. In the design performed, the role was played by a substantial existing refrigerator. The selection was made with regard to the manufacturer's decision to launch a new refrigerator model on overseas markets with high environmental requirements. Along with the decision on launching a new (prepared) product on the demanding market, it was assumed to take up an advertising-information campaign in order to present the ecodesign results. The trend to achieve the position of the national leader in the scope of ecodesign application was also important, which resulted in the introduction of innovative solutions. The reference object presents a set of input characteristics, so it should be well characterized (step 1.3.2 in ecodesign procedure, as proposed in Lewandowska and Kurczewski 2010). Within the example presented, a twocompartment fridge of the compressor group was selected.

The refrigeration compartment capacity is 2261 , whereas that of the freezing compartment is 921 . The refrigerator is of $\mathrm{A}+$ energetic class and the annual average power consumption is $252 \mathrm{kWh}$, which corresponds to $0.69 \mathrm{kWh}$ a day. The refrigerating system consists of two independent cycles for the refrigerating and freezing compartments. The refrigerant is R600a (isobutane). The dimensions of the refrigerator assumed as the reference object are as follows:

- height, $1850 \mathrm{~mm}$;

- width, $595 \mathrm{~mm}$;

- depth, $600 \mathrm{~mm}$.

There are five glass shelves in the refrigerating compartment four of which are removable. Moreover, there are two food containers there, two vegetable cabinets, bottle hanger, six removable multi-box containers, and two plastic shelves. The overall weight of the refrigerator is $94.6 \mathrm{~kg}$. Various structural solutions were applied in it, which is the reason for the variety of the materials used. The inventory table developed presents 140 materials identified.

Furthermore, the production process structure has been defined and the following individual processes specified:

- sheet metal cutting,

- casing jacket profiling,

- door jacket profiling,

- preparing the surface and painting,

- polystyrene panel production,

- thermal forming,

- plastic injection,

- assembly of evaporators,

- foam application on the doors of the freezer and fridge,

- pre-assembly,

- foam application on the casings,

- artwork printing,

- final assembly.

The structural manufacturing data collected allowed the division of the production process into unit processes and attribute inputs and outputs to each. As a result, information on the consumption of raw and auxiliary materials, semifinished products, emissions to the air, water and soil, 
consumption of power and water, and the waste amount upon considering the efficiency and process losses, first for the particular unit processes and then for the whole product system. Data collected in this way became the basis for assessing the LCA and the LCC, corresponding to steps 1.3.3 and 1.3.4 of the ecodesign procedure applied and presented in (Lewandowska and Kurczewski 2010). The performance of the third type of tests-assessment of the social aspects in the life cycle (Section 1.3 of the procedure) was deliberately omitted, motivating the fact by still uncertain action methodology in this scope. Based on the results of the LCA and LCC analyses, the following ecodesign have been formulated (Section 1.3) concerning the refrigerator being the reference object:

- Power consumption reduction at the usage stage,

- reduction of environmental effects related to the cooling system with particular consideration to the compressor effect,

- reliability improvement,

- cost reduction of materials used in the production.

\subsection{Definition of the target condition}

While performing another stage of the procedure, the ecodesign team defined the interested parties appearing in the reference refrigerator's life cycle (step 1.4.1 in ecodesign procedure, as proposed in Lewandowska and Kurczewski 2010). The stakeholders were identified including the division into those originating from the internal and external environment. Further on, based on the criteria presented in the first part of the paper their assessment and hierarchization were made (step 1.4.2 in ecodesign procedure) (Lewandowska and Kurczewski 2010). The results of this action are presented in Table 1 . It is worth emphasizing that the importance coefficients attributed to particular interested parties may differ in various designs, depending on the assumed ecodesign target and scope of research.

Following the methodology developed, it was assumed that those stakeholders who obtained three to five importance coefficients will be considered in the further performance of the design. Within the example presented, they include: firm owners, employees, users, competitors, recyclers, and ecomarking entities as well as those implementing the WEEE, RoHS Directives. Further on, the information on the interested parties' requirements was collected (step 1.4.3 in ecodesign procedure, as proposed in Part 1) (Lewandowska and Kurczewski 2010). In order to facilitate the communication and simplify the information collecting method, the ecodesign team developed a list of requirements and passed it to interested parties on appropriate forms. The preparation of the requirements' list was preceded by the survey performed among the customers and the series of meetings with the key persons from the company (directors of the particular departments, technologists and designers, service staff, etc.). The list included the requirements recognized as significant from the point of view of all the parties interested potentially appearing in the fridge freezer's life cycle. While filling in the forms, the stakeholders attributed importance coefficients in the scale of $0-10$ to each particular requirement. It is worth mentioning that the forms contained blank spaces enabling the attribution of additional requirements.
Table 1 Interested parties assessment results

\begin{tabular}{ll}
\hline Interested parties & Importance coefficient (0-5) \\
\hline Internal environment & 5 \\
Firm owners & 4 \\
Employees & \\
External environment & 2 \\
Raw material and semi-finished product suppliers & 5 \\
Fridge freezer users (actual and potential users/target customers) & 5 \\
Competitors & 2 \\
Logistic-forwarding company & 3 \\
Recycling organizations & 2 \\
Service repair units & 2 \\
Retailers & 2 \\
Home appliance recyclers & 2 \\
Ecological associations & 2 \\
Consumer associations & 2 \\
Lobby & 2 \\
Ecomarking: EU ecomark & 5 \\
Public and local administration & 4 \\
\hline
\end{tabular}




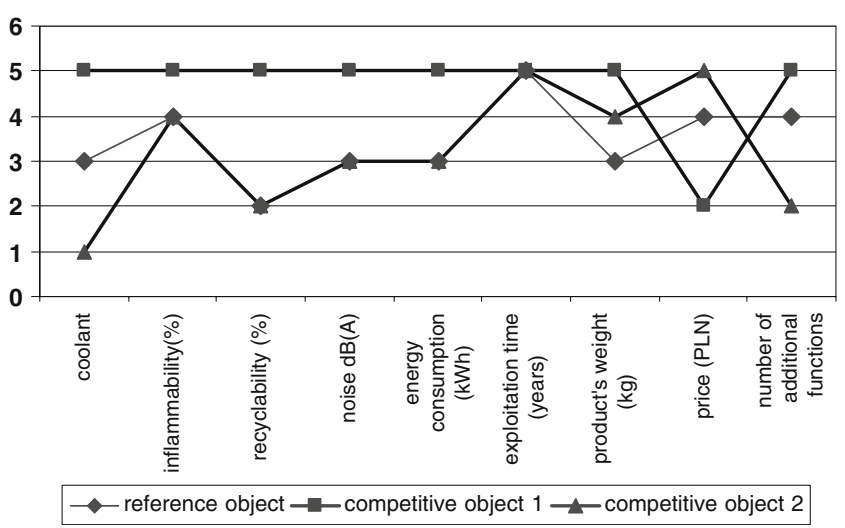

Fig. 1 Environmental benchmarking results for the reference object

In order to expand the information on the significant requirements, the environmental benchmarking (EB) for competitive products was carried out (Wimmer and Zust 2002; Wimmer et al. 2004), the results of which are shown in Fig. 1. From the environmental benchmarking, the following conclusions result (the EB results were considered in the most important requirements selection process):

- the reference object analyzed appears worse in case of almost all the assessment criteria (except the price and usage time) than the competitive object 1 ,

- the reference object shows slight differences as compared to the competitive object 2; the reference object refrigerant is more environment friendly and the object has more additional functions;

- the biggest difference as compared to the competitive object 1 appears within the following criteria: the refrigerant, recyclability, noise, power consumption and the product weight.

Based on the significance coefficients attributed by key interested parties to the particular requirements, those were selected out of these coefficients that became the basis for ecodesign task formulation. Due to the fact that the benchmarking results provided information on the requirements without the option to attribute significance coefficients to them (the competitors did not receive forms to be filled in), therefore it was assumed that the requirements formulated based on the benchmarking were treated directly as ecodesign recommendations. Upon summing up, the significance coefficient products of interested parties and the particular requirements, it was acknowledged that those requirements that obtained the total result above 21 points, which represented $3 \%$ of the total (performed as a step 1.4.4 of ecodesign procedure), shall be subject to further analysis. As competitors were recognized a significant stakeholders, the selected requirements also included the benchmarking results. Summarizing, the following requirements will be analyzed in the further stages of the procedure:

- elimination of the use of toxic compounds during the production $(3.33 \%)$,

- increased share of recyclable materials $(4.36 \%)$,

- disassembly time reduction $(3.93 \%)$,

- use of recycled materials $(3.93 \%)$,

- considering the whole life cycle during product design $(4.52 \%)$,

- restricted number of inseparable connections (3.74\%),

- providing spare parts availability (4.52\%),

- reduced power consumption at the usage stage (4.52\%),

- extending the warranty and usability periods (3.33\%),

- noise level reduction during operation (3.33\%),

- marking the materials (4.68\%),

- assuring usage compliant with environment protection requirements $(3.33 \%)$,

- following the policy of returning the used products $(5.12 \%)$, reaching the levels of collection of obsolete products $(4.28 \%)$.

\subsection{Formulation of conclusions from the planning stage}

The set of requirements resulting from the planning stage of the ecodesign procedure developed appeared to be very wide. It included the requirements whose fulfillment is brought most of all to the changes in the materials used (including the implementation of recycled materials) and the requirements formulated in a fairly general way. Moreover, there are requirements whose fulfillment is brought to implementation of new organizational solutions in the sphere of influencing the customer attitudes. Such a variety of requirements caused the necessity for their selection-it was made at the stage of preparing the conceptual design.

\section{Conceptual design}

At the stage of formulating the ecodesign tasks, the information that constitutes the set of recommendations and requirements originating from: the LCA and LCC analyses, surveys of the interested parties and benchmarking was analyzed. Based on the said analyses, the following ecodesign tasks were formulated (step 1.4.5 of ecodesign procedure, as presented in Lewandowska and Kurczewski 2010):

1. achievement of a higher energetic efficiency class $(\mathrm{A}++)$ and power consumption reduction to $218 \mathrm{kWh} /$ year (reduction by $13.5 \%$ compared to the reference object power consumption) 
2. reduction by $25 \%$ of the number of toxic substances

3. noise reduction at the operation stage by $38 \mathrm{~dB}(\mathrm{~A})$

4. obtaining the recyclability index at the level of $80 \%$

5. disassembly time reduction to $30 \mathrm{~min}$

6. product weight reduction by $5 \%$ as compared to the weight of the reference object,

7. providing the availability of spare parts for 12 years from the production date

8. providing service repairs for 12 years from the production date

9. marking the materials

10. developing an appropriate system and providing the possibility of return of the used appliances.

Tasks $7-10$ are of a qualitative nature; therefore, they were not included in the multi-criteria analysis made at stage 2.3 of the ecodesign procedure. Moreover, they will assume the same levels, disregarding the design solution. So the decision to consider them was made at the detailed design stage only. Based on the ecodesign tasks the variants were determined and assessed by means of the multidimensional comparative analysis (MCA). Table 2 presents variants of solutions considered in the example presented herein, i.e. the refrigerator ecodesign.

During further ecodesign stages (steps 2.3, as presented in Part 1), the multicriteria analysis was taken up and the nature of the criteria was determined by the target that may be the minimization or maximization of a given criterion's value. The result of the above is presented in Table 3. One of the elements included in Table 3 is criterion's significance coefficient being the most subjective element of the MCA procedure. It depends on attributing the weighting factors to each criteria. In the presented example the factors are proposed and determined by the ecodesign team, butwhat should be very clearly stressed - it is possible to perform MCA analysis without this step. The weighting can be included if evident differences in criteria's relevance exist. If used, an execution of sensitivity analysis could be recommended. As presented in Table 4, in our example the results of MCA are similar, with and without the weighting.

Furthermore, the unification of all the criteria was made. Due to the fact the only one (recyclability index) of the seven criteria is a stimulant, it was decided to replace this criterion with a destimulant. Such a replacement meant division of "1" by the values assumed as the "recyclability" index. Then the ecodesign team defined the particular criteria values that may be reached within the ten suggested ecodesign variants in order to commence the characteristic standardization (the values assumed by the criteria). As a result of the standardization, a matrix including the standardized characteristic values that were subjected to aggregation.

Table 2 Ecodesign task performance variants

\begin{tabular}{|c|c|c|}
\hline Ecodesign task & Variant description & Variant number \\
\hline \multirow[t]{5}{*}{ Power consumption reduction to $218 \mathrm{kWh} /$ year } & Replacement of the refrigerating unit with a more efficient one & Variant 1 \\
\hline & Change of the number of refrigerating units & Variant 2 \\
\hline & Replacement of the refrigerant with a one of higher energetic efficiency & Variant 3 \\
\hline & Improvement of the refrigerator insulation & Variant 4 \\
\hline & Replacement of traditional electrical refrigerating units with magnetic ones & Variant 5 \\
\hline \multirow[t]{5}{*}{ Noise reduction to $38 \mathrm{~dB}(\mathrm{~A})$} & $\begin{array}{l}\text { Application of elements damping vibrations during the refrigerating unit's } \\
\text { operation }\end{array}$ & Variant 6 \\
\hline & Replacement of traditional electrical refrigerating units with magnetic ones & Variant 5 \\
\hline & Replacement of the refrigerating unit with a more efficient one & Variant 1 \\
\hline & Change of the number of refrigerating units & Variant 2 \\
\hline & Improvement of the refrigerator insulation & Variant 4 \\
\hline \multirow[t]{2}{*}{ Restriction of toxic substances by $25 \%$} & Replacement of the refrigerant with a more environmental friendly one & Variant 3 \\
\hline & Removal of the chloride paraphin inflammability reduction agents & Variant 7 \\
\hline \multirow[t]{3}{*}{ Reduction of disassembly time to $30 \mathrm{~min}$} & Reduction of the number of inseparable connections by $10 \%$ & Variant 8 \\
\hline & Reduction of the amount of material by $5 \%$ & Variant 9 \\
\hline & Change of the number of refrigerating units & Variant 2 \\
\hline \multirow[t]{3}{*}{ Reduction of the product's weight } & Change of the number of refrigerating units & Variant 2 \\
\hline & Reduction of the amount of material by $5 \%$ & Variant 9 \\
\hline & Restriction of the package weight & Variant 10 \\
\hline \multirow{2}{*}{$\begin{array}{l}\text { Obtaining recyclability index on the level } \\
\text { of } 80 \%\end{array}$} & Reduction of the amount of material by $5 \%$ & Variant 9 \\
\hline & Replacement of the toxic index with a more environmental friendly one & Variant 3 \\
\hline
\end{tabular}


Table 3 Determination of the criteria nature by ecodesign target

\begin{tabular}{|c|c|c|c|c|c|c|c|}
\hline Criterion & Toxic substances & $\begin{array}{l}\text { Power } \\
\text { consumption in } \\
\text { operation }\end{array}$ & Noise & Disassembly & $\begin{array}{l}\text { Product } \\
\text { weight }\end{array}$ & $\begin{array}{l}\text { Recyclability } \\
\text { rate }\end{array}$ & Refrigerant \\
\hline $\begin{array}{l}\text { Type of characteristic/stimulant, } \\
\text { destimulant, nominant/ }\end{array}$ & $\mathrm{D}$ & $\mathrm{D}$ & $\mathrm{D}$ & $\mathrm{D}$ & $\mathrm{D}$ & $\mathrm{S}$ & $\mathrm{D}$ \\
\hline Target/min, $\max$ & Min & Min & Min & Min & Min & Max & Min \\
\hline Unit & $\begin{array}{l}\text { Number of toxic } \\
\text { substances [number] }\end{array}$ & $\begin{array}{l}\text { Power } \\
\text { consumption } \\
\text { [kwh/year] }\end{array}$ & $\begin{array}{l}\text { Noise } \\
\text { emission [db (a)] }\end{array}$ & $\begin{array}{l}\text { Disassembly } \\
\text { time [min] }\end{array}$ & $\mathrm{kg}$ & {$[\%]$} & GWP \\
\hline $\begin{array}{l}\text { Criterion's significance } \\
\text { coefficient }\end{array}$ & 0.1 & 0.3 & 0.2 & 0.15 & 0.05 & 0.1 & 0.1 \\
\hline Variant 1 & 4 & 230 & 39 & 60 & 80 & 72 & 20 \\
\hline Variant 2 & 3 & 218 & 38 & 40 & 70 & 70 & 20 \\
\hline Variant 3 & 3 & 230 & 41 & 60 & 77 & 72 & 0 \\
\hline Variant 4 & 3 & 220 & 39 & 50 & 80 & 75 & 20 \\
\hline Variant 5 & 4 & 230 & 38 & 55 & 80 & 75 & 20 \\
\hline Variant 6 & 4 & 252 & 38 & 65 & 82 & 75 & 20 \\
\hline Variant 7 & 2 & 252 & 41 & 60 & 77 & 70 & 20 \\
\hline Variant 8 & 4 & 252 & 41 & 30 & 76 & 70 & 20 \\
\hline Variant 9 & 4 & 252 & 41 & 38 & 74 & 80 & 20 \\
\hline Variant 10 & 4 & 252 & 41 & 60 & 74 & 72 & 20 \\
\hline $\begin{array}{l}\text { Criterion's input value } \\
\text { (reference product) }\end{array}$ & 4 & 252 & 41 & 60 & 78 & 70 & 20 \\
\hline $\begin{array}{l}\text { Criterion's target value } \\
\text { (ecodesign tasks) }\end{array}$ & 3 & 218 & 38 & 30 & 74 & 80 & 3 \\
\hline
\end{tabular}

In virtue of the MCA analysis the values of the so-called synthetic development measures (SDM) were obtained for each of the variants. The lower the SDM value the shorter was the distance between each variant and the target values for the particular criteria. The variants were assessed on two platforms:

- the extent of fulfillment of the particular criteria-the closer was a variant to the target value the better,

Table 4 SDM values for the particular variants

\begin{tabular}{lll}
\hline Variant & SDM (with weighting) & SDM (without weighting) \\
\hline Variant 1 & 0.022 & 0.29 \\
Variant 2 & 0.015 & 0.19 \\
Variant 3 & 0.008 & 0.14 \\
Variant 4 & 0.015 & 0.21 \\
Variant 5 & 0.021 & 0.27 \\
Variant 6 & 0.025 & 0.32 \\
Variant 7 & 0.028 & 0.31 \\
Variant 8 & 0.028 & 0.23 \\
Variant 9 & 0.026 & 0.23 \\
Variant 10 & 0.027 & 0.30 \\
\hline
\end{tabular}

- the number of criteria met - the better a given variant the more criteria will be met thanks to its fulfillment.

The SDM values for the particular criteria (with or without weighing) of the criteria are presented in Table 4.

Three variants of changes being the result of ecodesign algorithm became the basis for the conceptual refrigerator's design development: 2 (change of the number of refrigerating units), 3 (refrigerant replacement), and 4 (refrigerator's insulation improvements). Several resultant structural concepts being the response to the change variants were assessed in terms of feasibility and implementability. They became the subject of detailed analyses at the stage of the detailed design creation.

\section{The detailed design}

At the stage of the fridge freezer detailed design formation, more details were added and the conceptual designs and their variants were made more specific. It was proven that there were a few options to obtain the targets set providing the intended environmental-economic optimization. Those that did not require implementation of significant changes in the production process (i.e., did not increase the 


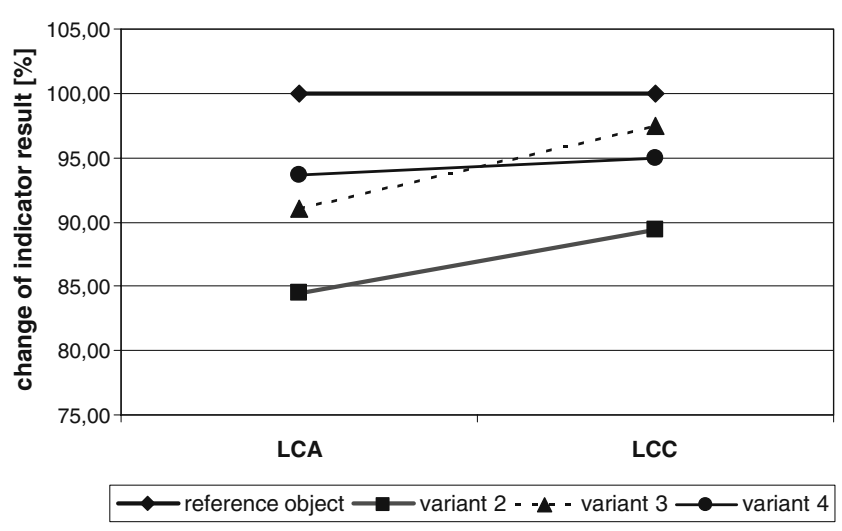

Fig. 2 Environmental and economic results of ecodesign task performance variant implementation

production costs significantly) were acknowledged worth consideration in the first place. They included:

- The replacement of the R600a refrigerant (isobutane) with RC270 (cyclopropane),

- the replacement of the PUR insulation material with its variety (PIR), characterized with a lower heat conductivity index.

The justifiability of the suggested change is confirmed with the results of tests known from the references, which explicitly proves that the RC270 agent, compared to the R600a, is significantly more environment friendly and at the same time has better energetic efficiency parameters. Moreover, it is possible to replace the R600a agent with the RC270 without any structural modifications in the construction of the particular fridge freezer elements. The PIR (polyisocyanourate) foam has a lower heat conductivity as compared to the PUR foam. The values of this parameter are PUR, $0.026 \mathrm{~W} / \mathrm{m} \cdot \mathrm{K}$; and PIR, $0.021 \mathrm{~W} / \mathrm{m} \cdot \mathrm{K}$, respectively. In the case of a modification in the insulation foam, however, the changes in the technology of filling the casing with the foam would be necessary. The third significant change considered during the formation of the detailed designs is restricting of the number of the refrigerating units from two to one. The expected benefits resulting from such a measure are of both environmental and economic nature. Such a change, however, brings about significant technological changes and major modification of the fridge freezer designed.

\section{Tests}

Within the fourth stage of the ecodesign procedure, tests are carried out in order to find the answer to the question which of the variants selected upon the multicriteria analysis is the best. The data included in the specification of the detailed designs constitute the basis for the tests performed. The LCA, LCC analyses SLCA are made in virtue thereof. The test results concerning three selected variants are presented in Fig. 2 and Table 5. In the presented example, the single score was used as the environmental indicator. Ecodesign is treated here as an internal application of LCA and the ecodesign results are intended to be used for the internal purposes, so the LCA procedures including weighing are possible to use. It does not exclude a possibility of use of the results on the environmental profile level, but it can make the ecodesign procedure more difficult and too complicated.

Based on the analyses, it is suggested that variant 2 should be selected for the test stage (prototyping, tests, test production) because it is characterized with the highest reduction extent of the environmental impact and costs occurring throughout the whole life cycle of the product analyzed. The environmental effect reduction reaches $15.47 \%$, and that of the economic index $10.56 \%$. All the variants analyzed show lower values of environmental economic costs as compared to the reference object, while the benefits obtained from the implementation of variant 2 are the highest. Variant 2 (the compressor) shows that the comparable production costs (lower number of materials used, however, the necessity to match the equipment to the

Table 5 Ecodesign task variant performance results

\begin{tabular}{|c|c|c|c|c|c|}
\hline & Stage & Production (\%) & Usage $(\%)$ & Recycling (\%) & Whole life cycle $(\%)$ \\
\hline Basic version & Environmental indicator $[\mathrm{Pt}]$ & $52.09(0.00)$ & $148.01(0.00)$ & $-14.80(0.00)$ & $185.30(0.00)$ \\
\hline Variant 2 & & $41.58(\downarrow 20.18)$ & $128.49(\downarrow 13.19)$ & $-13.43(\uparrow 9.26)$ & $156.64(\downarrow 15.47)$ \\
\hline Variant 3 & & $51.81(\downarrow 0.54)$ & $134.73(\downarrow 8.97)$ & $-17.75(\downarrow 19.93)$ & $168.79(\downarrow 8.91)$ \\
\hline Variant 4 & & $52.07(\downarrow 0.04)$ & $136.21(\downarrow 7.97)$ & $-14.80(\downarrow 0.00)$ & $173.48(\downarrow 6.38)$ \\
\hline Basic version & Economic indicator $[\mathrm{PLN}]$ & $644.00(0.00)$ & $1,186.35(0.00)$ & $60.00(0.00)$ & $1,890.35(0.00)$ \\
\hline Variant 2 & & $635.00(\downarrow 1.40)$ & $1,002.75(\downarrow 15.48)$ & $53.00(\downarrow 11.67)$ & $1,690.75(\downarrow 10.56)$ \\
\hline Variant 3 & & $675.00(\uparrow 4.81)$ & $1,112.15(\downarrow 6.25)$ & $55.00(\downarrow 8.33)$ & $1,842.15(\downarrow 2.55)$ \\
\hline Variant 4 & & $660.00(\uparrow 2.48)$ & $1,078.35(\downarrow 9.10)$ & $57.00(\downarrow 5.00)$ & $1,795.35(\downarrow 5.00)$ \\
\hline
\end{tabular}


new compressor), lower usability costs (lower power consumption), lower recycling costs, as compared to variants 3 and 4 .

\section{Launching on the market and product verification}

The implementation of the product on the market is the first stage of its life cycle from the marketing point of view. As the sales growth rate is slow, it is usually difficult to control the ecodesign measure results (including the assumptions taken therein) within a short time and implement improvements aimed at better structural or organizational solutions. This also concerns the case presented, prepared based on ecodesign procedure prepared for the object-fridge freezer.

The only fact that requires to be emphasized is that the launching of a product designed based on the ecodesign concept should always, in any circumstances, be accompanied by announcement thereof, through any environmental communication channels available. It is aimed at informing the market on the ecodesign endeavor taken and results obtained. In the case of the fridge freezer example described, one of the environmental communication methods is to put the European environmental mark on the casing of the appliance.
The further measures inscribed in the ecodesign procedure will be taken in the future when it is possible to obtain feedback from the market (interested parties) whether the product designed and manufactures really meets the requirements. Based on the information obtained, the verification of the fridge freezer design will be made and further modifications implemented, if necessary.

Open Access This article is distributed under the terms of the Creative Commons Attribution Noncommercial License which permits any noncommercial use, distribution, and reproduction in any medium, provided the original author(s) and source are credited.

\section{References}

Lewandowska A, Kurczewski P (2010) ISO 14062 in theory and practice - ecodesign procedure. Part 1: structure and theory. Int J Life Cycle Assess 15(9) online first doi:10.1007/s11367-0100228-8

Wimmer W, Zust R (2002) Ecodesign pilot product investigation, learning and optimization - tool for sustainable product development. ISBN 978-4020-1090-3

Wimmer W, Zust R, Lee KM (2004) Ecodesign implementation: a systematic guidance on integrating environmental considerations into product development. Springer ISBN 9781402030703 